\title{
Newton-Raphson State Estimation Solution Employing Systematically Constructed Jacobian Matrix
}

\author{
Nursyarizal Mohd Nor, Prof. Dr. Ramiah Jegatheesan \\ and Ir. Perumal Nallagowden \\ University Technology PETRONAS \\ Malaysia
}

\section{Introduction}

State Estimation (SE) in power systems is considered as the heart of any energy control center. It is responsible for providing a complete and reliable real-time data-base for analysis, control, and optimization functions (A. Monticelli 2002). Since electric power system state estimation was introduced by F. C. Schweppe et. al. 1970, it has remained an extremely active and contentious area. Nowadays, state estimation plays an important role in modern Energy Management systems (EMS) providing a complete, accurate, consistent and reliable database for other functions of the EMS system, such as security monitoring, optimal power flow, security analysis, on-line power flow studies, supervisory control, automatic voltage control and economic dispatch control (A. Monticelli 2002, F. C. Schweppe et. al. 1970, Ali Abur \& A. G. Exposito 2004). The energy control centers gather information and measurements on the status and state of a power system via Supervisory Control and Data Acquisition System (SCADA).

Various methods for state estimation have been introduced (A. Monticelli 2002, F. C. Schweppe et. al. 1970, Holten et. al. 1988 and A Garcia et. al. 1979) in the past. Among those methods, Weighted Least Squares (WLS) algorithm is the most popular and finds applications in many fields. In WLS method the measured quantities are represented as sum of true values and errors as

$$
z=h(x)+e
$$

where $z$ is the measurement vector, consisting of real and reactive power flows, bus injection powers and voltage magnitudes; $x$ is the true state variable vector, consisting of bus voltage magnitudes and bus voltage angles; $h(x)$ is the non-linear function that relates the states to the ideal measurements; $e$ is a vector of measurement errors. A state estimate $\hat{x}$ is to be obtained that minimizes the objective function $f$ given by 


$$
f=\sum_{j=1}^{m} w_{j} e_{j}^{2} \text { or } \sum_{j=1}^{m} \frac{e_{j}^{2}}{\sigma_{j}^{2}}
$$

and this can be achieved when

$$
\sum_{j=1}^{m} 2 w_{j} e_{j} \frac{\partial e_{j}}{\partial x_{n}}=0
$$

where ' $w_{j}^{\prime}$ ' is the weighting factor for the respective measurement, $m=1,2, \ldots$, number of measurements and $n=1,2, \ldots$, number of state variables. This non-linear least squares problem is usually solved iteratively as a sequence of linear least squares problem. At each step of the iteration, a WLS solution to the following noise-corrupted system of linear equation is sought:

$$
\hat{e}=z-\hat{z}=z-H \hat{x}=e-H(\hat{x}-x)
$$

In Eq. 4, $e$ is the measurement residual vector, the difference between the actual measurement vector and the value of $h(x)$ at the current iteration, $\hat{x}-x$ is the difference between the updated state and the current state, $H$ is the Jacobian of $h(x)$ in Eq. 1 at the current iteration. The flow of SE solution algorithm is shown in Figure 1.

Although the function of a SE is understandable, there is much freedom of choice in its practical implementation. One of the important options is that of the statistical methodology used to filter the measured data. The basic Newton-Raphson WLS method, when used in power systems, has good convergence, filtering and bad data processing properties, for a given observable meter placement with sufficient redundancy and yields optimum estimates. However, the gain and the Jacobian matrices associated with the basic algorithm require large storage and have to be evaluated at every iteration, resulting in very long computing time. The essential requirements for any on-line SE are reliability, speed and less computer storage. The computational burden associated with the basic WLS algorithm makes it unsuitable for on-line implementation in large scale power systems.

\section{State of the Art}

One of the main steps in the algorithm of WLS is creating and updating the Jacobian matrix, $H$, which is significantly time consuming step which requires a large number of floating point multiplication. Fred Schweppe et. al. in their paper had modified the basic WLS algorithm purposely for real time application in large scale power system (F. C. Schweppe \& E. J. Handschin 1974). In that paper, the constant gain and Jacobian matrices are used in order to reduce the computational time. However, WLS processing could still need a longer time for medium to large networks and becomes even longer in the presence of multiple data with gross error and the procedures for bad data processing. Since then, several different alternatives to the WLS approach have been investigated.

Some of the algorithms developed and implemented in real time are sequential estimators,orthogonal transformation methods, hybrid method and fast decoupled 
estimators (A Garcia et. al. 1979 and A. Monticelli \& A Garcia 1990). In sequential state estimation, each measurement is processed sequentially, usually one at time. Processing of the measurement is done by avoiding the matrix procedures. Thus, the objective of sequential state estimation is mainly intended to provide computational efficiency both in terms of computing time and storage requirements. Sequential estimators have so far been found to be practical for small networks, but not for medium to large networks. In orthogonal transformation methods (A. Simoes-Costa \& V. H. Quintana Feb. 1981, A. Simoes-Costa \& V. H. Quintana August 1981, Ali Abur \& A. G. Exposito 2004 and A. Monticelli 2002), there is no need to compute the gain matrix. The measurements are transformed into virtual measurements that are functions of the state and of the original measurements. However, the only concern of this method is the need to obtain the orthogonal matrix which, in spite of being actually expressed as the product of elementary matrices, is much denser than the gain matrix which can slower the computational speed. Some ideas, such as Hybrid method (Slutsker I.W. Vempatin \& W.F. Tinney 1992) has been proposed to speed up orthogonal factorization. This method does not require the storage of the orthogonal matrix and it can easily be implemented in the efficient fast decoupled version. However, according to Holten, L et al. 1988 and Slutsker I.W. Vempatin \& W.F. Tinney 1992, this method is less stable than the orthogonal transformation method and also it remains rather slower compared with the normal equation method. The WLS formulation may be decoupled by separating the measurement set into real and reactive power groups and by using the same simplifying assumptions as used in the fast decoupled load flow (B Stott \& O Alsac 1974). The integrated SE like fast decoupled state estimation may not meet the requirements of on-line state estimation in terms of computer storage and time for very large scale power systems containing thousand or more busses. The reduction of the computation burden that fit with normal equation of SE needs further investigation. 


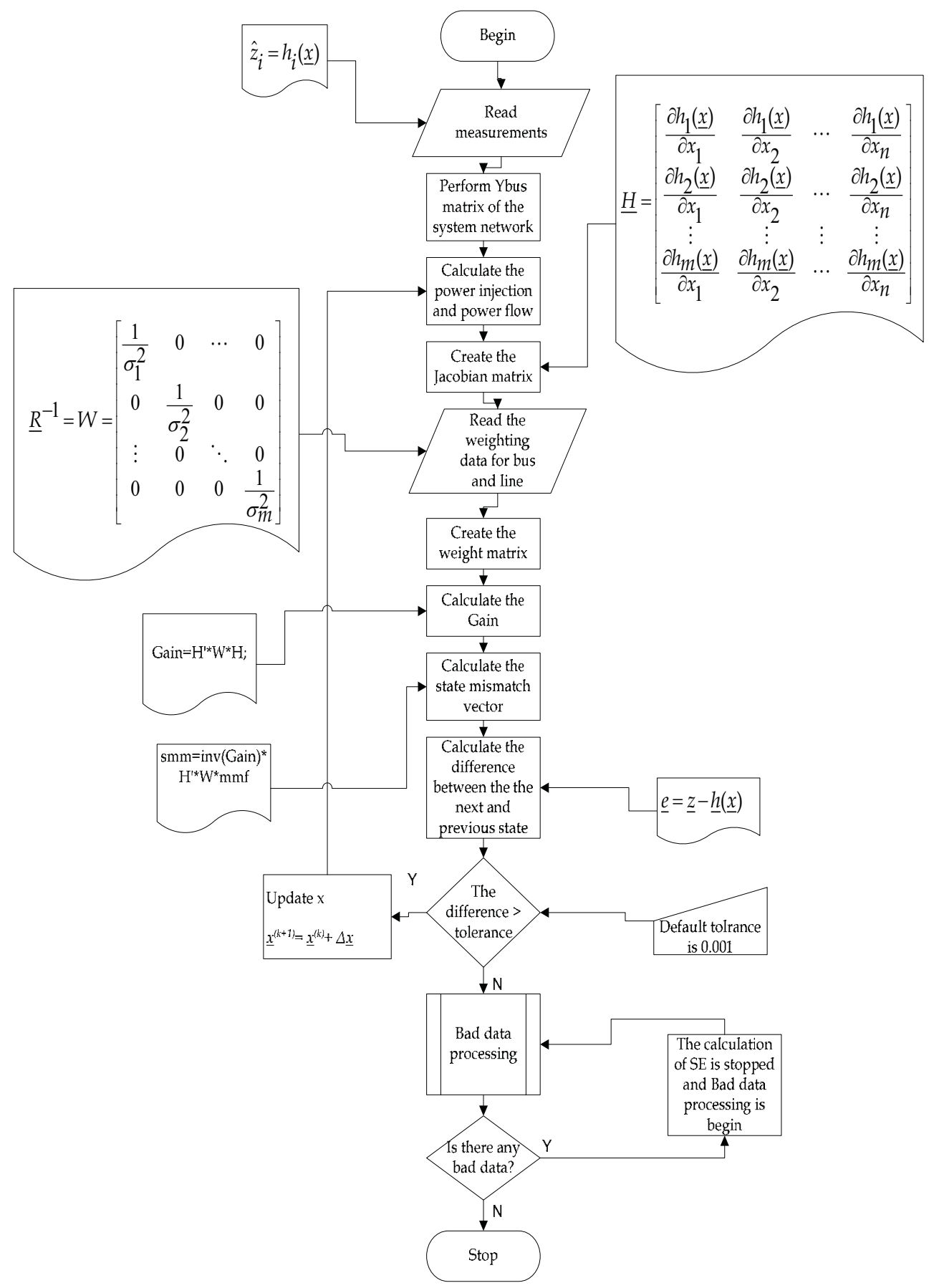

Fig. 1. State Estimation Solution. 


\section{Contribution}

In the Newton-Raphson State Estimator (NRSE) method, the process of computing the elements of the Jacobian matrix is significantly time consuming step which requires evaluation of large number of trigonometric functions. It is significant, especially in large scale power system networks. Fast Decoupled State Estimator (FDSE) (A. Monticelli 2002, A Garcia et. al. 1979 and Ali Abur \& A. G. Exposito 2004) are based on assumptions that in practical power system networks under steady-sate, real power flows are less sensitive to voltage magnitudes and are very sensitive to voltage phase angles, while reactive power flows are less sensitive to voltage phase angles and are very sensitive to voltage magnitudes. Using these properties, the sub-matrices $H_{P, V}, H_{p i j, V}, H_{p j i, V}, H_{Q, \delta}, H_{q i j, \delta}$ and $H_{q j i, \delta}$ are neglected. Because of the approximations made, the corrections on the voltages computed in each iteration are less accurate. This results in poor convergence characteristic. Newton-Raphson State Estimator (NRSE) method (Ali Abur \& A. G. Exposito, 2004, A. Monticelli 1999, John J. Grainger \& William D. Stevenson Jr. 1994 and Stagg,G.W. \& El-Abiad, A.H. 1968) that was subsequently introduced became more popular because of exact problem formulation and very good convergence characteristic. In NRSE method, elements of Jacobian matrix are computed from the standard expressions which are functions of bus voltages, bus powers and the elements of bus admittance matrix. Nowadays, with the advent of fast computers, even huge amount of complex calculations can be carried out very efficiently.

The aim of this research is to reduce the time taken to construct the $H$ matrix. A simple algorithm to construct the $\mathrm{H}$ matrix is presented in this chapter. This algorithm can be easily fit into the Newton Raphson State Estimation method. It is recognized that each element of the Jacobian matrix is contributed by the partial derivatives of the power flows in the network elements. The elements of the state estimation Jacobian matrix are obtained considering the power flow measurements in the network elements. The proposed algorithm will process the network elements one-by-one and the elements of $H$ matrix are updated in a simple manner. The final $H$ matrix thus constructed is exactly same as that obtained in available NRSE method. The details of the proposed algorithm are discussed in the following sections.

\section{General Structure of $\boldsymbol{H}$ matrix}

The SE Jacobian $H$, is not a square matrix. The $H$ matrix always has $(2 N-1)$ columns, where $N$ is equal to number of buses. The number of rows in $H$ matrix is equal to number of measurements available. For full measurement set, number of rows will be equal to $(3 N+4 B)$ where $B$ is number of lines. The elements of $H$ represent the partial derivates of bus voltage magnitudes, bus powers and line flows with respect to state variables $\delta$ and $V$. As shown in Eq. 5, $H_{V, \delta}, H_{V, V}, H_{p i j, \delta}, H_{p i j, V}, H_{p j i, \delta}, H_{p j i,}, H_{q i j, \delta}, H_{q i j, V}, H_{q j i, \delta}, H_{q j i,}, H_{P, \delta}, H_{P, V}$, $H_{Q, \delta}$ and $H_{Q, V}$ are the sub-matrices of Jacobian matrix. The first suffix indicates the available measurement and the second suffix indicates the variable on which the partial derivatives are obtained. The constructional details of the SE sub-matrices are discussed in Section 5.

\subsection{Power flows in network elements}

The transmission network consists of transmission lines, transformers and shunt parameters. In NRSE method the transmission network is represented by the bus 
admittance matrix and the elements of the $H$ matrix are computed using the elements of bus admittance matrix. Alternatively, in this chapter, the elements of the $H$ matrix are obtained considering the power flows in the transmission network elements.

Consider the transmission network element between buses $i$ and $j$, as shown in Figure 2 .

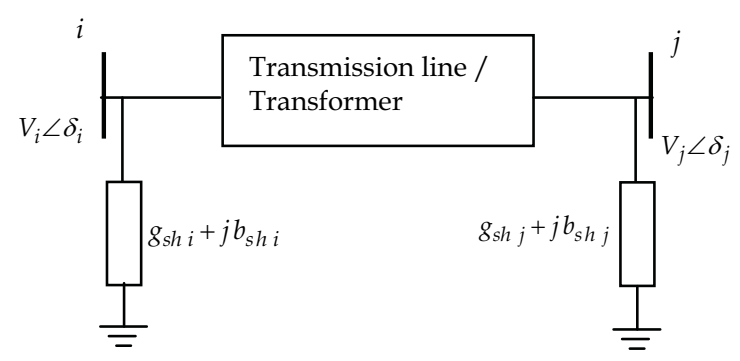

Fig. 2. Transmission network element between buses $i$ and $j$

The transmission line is represented by the series impedance $r_{i j}+j x_{i j}$ or by the corresponding admittance $g_{i j}+j b_{i j}$. Transformer with series impedance $r_{i j}+j x_{i j}$ and off-nominal tap setting " $a$ " with tap setting facility at bus $i$ is represented by the series admittance $\frac{1}{a}\left(g_{i j}+j b_{i j}\right)$ and shunt admittances $\left(\frac{1-a}{a^{2}}\right)\left(g_{i j}+j b_{i j}\right)$ and $\left(\frac{a-1}{a}\right)\left(g_{i j}+j b_{i j}\right)$ at buses $i$ and $j$ respectively. Half line charging admittance and external shunt admittance if any, are added together and represented as $g_{s h i}+j b_{s h i}$ and $g_{s h j}+j b_{s h j}$ at buses $i$ and $j$ respectively. For such a general transmission network element, the real and reactive power flows are given by the following expressions. 


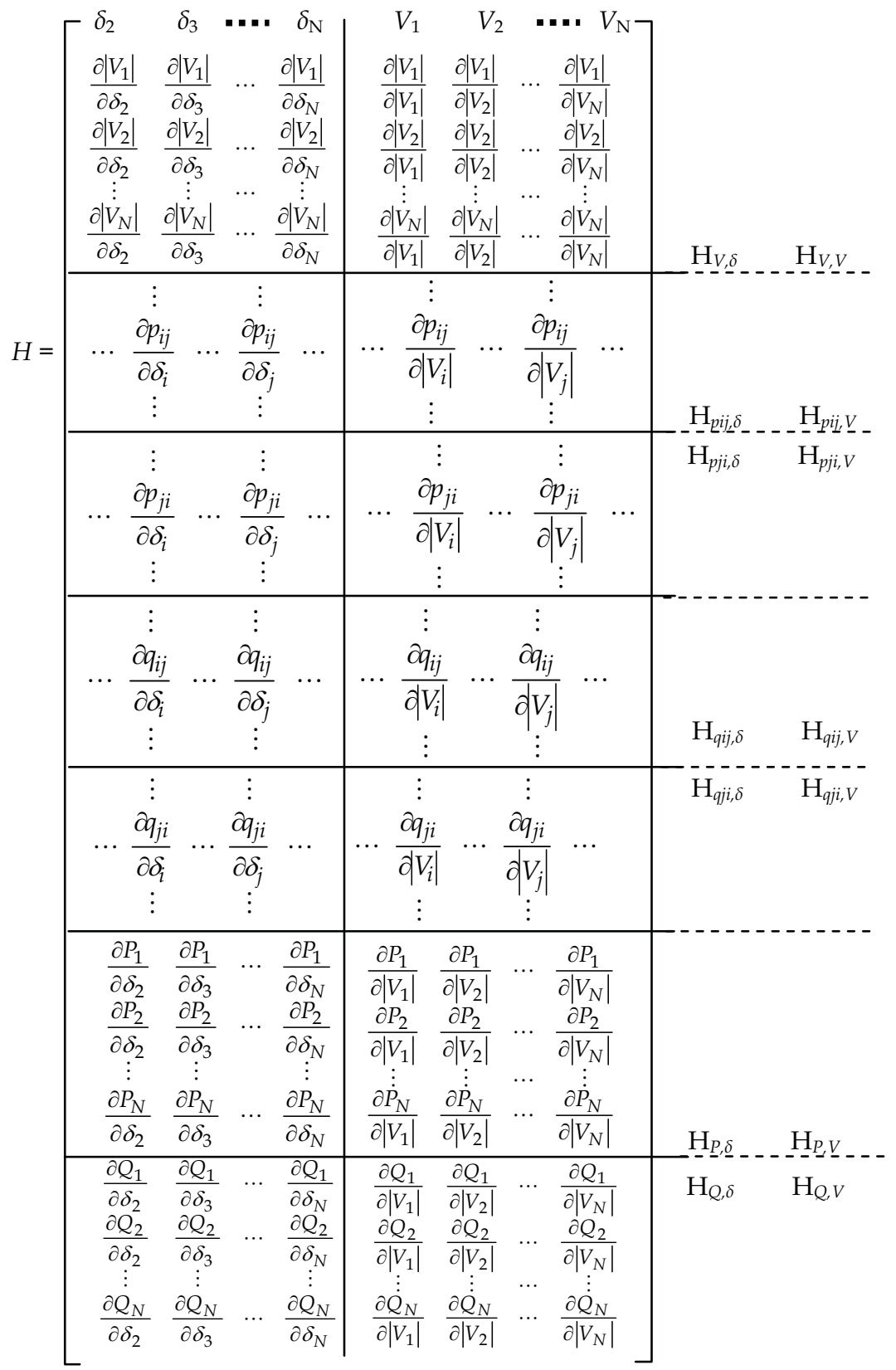




$$
\begin{aligned}
& p_{i j}=V_{i}^{2}\left(\frac{g_{i j}}{a^{2}}+g_{s h i}\right)-\frac{V_{i} V_{j}}{a}\left(g_{i j} \cos \delta_{i j}+b_{i j} \sin \delta_{i j}\right) \\
& p_{j i}=V_{j}^{2}\left(g_{i j}+g_{s h j}\right)-\frac{V_{i} V_{j}}{a}\left(g_{i j} \cos \delta_{i j}-b_{i j} \sin \delta_{i j}\right) \\
& q_{i j}=-V_{i}^{2}\left(\frac{b_{i j}}{a^{2}}+b_{s h i}\right)-\frac{V_{i} V_{j}}{a}\left(g_{i j} \sin \delta_{i j}-b_{i j} \cos \delta_{i j}\right) \\
& q_{j i}=-V_{j}^{2}\left(b_{i j}+b_{s h j}\right)+\frac{V_{i} V_{j}}{a}\left(g_{i j} \sin \delta_{i j}+b_{i j} \cos \delta_{i j}\right)
\end{aligned}
$$

where

$$
\delta_{i j}=\delta_{i}-\delta_{j}
$$

All the line flows computed from Eq. 6 to 9 are stored in the real power and reactive power matrix as in Eq. 11 and 12 from which bus powers can be calculated.

$$
\begin{aligned}
P & =\left[\begin{array}{ccccc}
0 & p_{12} & p_{13} & \cdots & p_{1 N} \\
p_{21} & 0 & p_{23} & \cdots & p_{2 N} \\
p_{31} & p_{32} & 0 & \cdots & p_{3 N} \\
\vdots & \vdots & \vdots & \vdots & \vdots \\
p_{N 1} & p_{N 2} & p_{N 3} & \cdots & 0
\end{array}\right] \\
Q & =\left[\begin{array}{ccccc}
0 & q_{12} & q_{13} & \cdots & q_{1 N} \\
q_{21} & 0 & q_{23} & \cdots & q_{2 N} \\
q_{31} & q_{32} & 0 & \cdots & q_{3 N} \\
\vdots & \vdots & \vdots & \vdots & \vdots \\
q_{N 1} & q_{N 2} & q_{N 3} & \cdots & 0
\end{array}\right]
\end{aligned}
$$

The real and reactive power flows in line $i-j$ depend on $\delta_{i}, \delta_{j}, V_{i}$ and $V_{j}$. The partial derivatives of $p_{i j}, p_{j i}, q_{i j}$ and $q_{j i}$ with respect to $\delta_{i}, \delta_{j}, V_{i}$ and $V_{j}$ can be derived from Eq. 6 to 9 .

\section{Construction of SE Jacobian Matrix, $\boldsymbol{H}$}

All the elements of $H$ matrix are partial derivatives of available measurements with respect to $\delta$ and $V$. The elements of sub-matrices $H_{V, \delta}, H_{V, V}$ are given by

$$
\begin{aligned}
& H_{V_{i}, \delta_{j}}=\frac{\partial V_{i}}{\partial \delta_{j}}=0 \mid \text { for all } i \text { and } j \\
& \left.H_{V_{i}, V_{j}}=\frac{\partial V_{i}}{\partial V_{j}}=0 \mid \begin{array}{l}
i \neq j \\
H_{V_{i}, V_{i}}=\frac{\partial V_{i}}{\partial V_{i}}=1
\end{array}\right\}
\end{aligned}
$$


If at particular bus, the voltage meter is not available, the row corresponding to that particular bus will be deleted.

Using Eq. 6 to 9 the expression for the partial derivatives of $p_{i j}, p_{j i}, q_{i j}$ and $q_{j i}$ with respect to $\delta_{i}, \delta_{j}, V_{i}$ and $V_{j}$ are obtained. Thus

$$
\begin{aligned}
& \frac{\partial p_{i j}}{\partial \delta_{i}}=\frac{V_{i} V_{j}}{a}\left(g_{i j} \sin \delta_{i j}-b_{i j} \cos \delta_{i j}\right) \\
& \frac{\partial p_{i j}}{\partial \delta_{j}}=-\frac{V_{i} V_{j}}{a}\left(g_{i j} \sin \delta_{i j}-b_{i j} \cos \delta_{i j}\right) \\
& \frac{\partial p_{i j}}{\partial V_{i}}=2 V_{i}\left(\frac{g_{i j}}{a^{2}}+g_{s h i}\right)-\frac{V_{j}}{a}\left(g_{i j} \cos \delta_{i j}+b_{i j} \sin \delta_{i j}\right) \\
& \frac{\partial p_{i j}}{\partial V_{j}}=-\frac{V_{i}}{a}\left(g_{i j} \cos \delta_{i j}+b_{i j} \sin \delta_{i j}\right) \\
& \frac{\partial p_{j i}}{\partial \delta_{i}}=\frac{V_{i} V_{j}}{a}\left(g_{i j} \sin \delta_{i j}+b_{i j} \cos \delta_{i j}\right) \\
& \frac{\partial p_{j i}}{\partial \delta_{j}}=-\frac{V_{i} V_{j}}{a}\left(g_{i j} \sin \delta_{i j}+b_{i j} \cos \delta_{i j}\right) \\
& \frac{\partial p_{j i}}{\partial V_{i}}=-\frac{V_{j}}{a}\left(g_{i j} \cos \delta_{i j}-b_{i j} \sin \delta_{i j}\right) \\
& \frac{\partial p_{j i}}{\partial V_{j}}=2 V_{j}\left(g_{i j}+g_{s h j}\right)-\frac{V_{i}}{a}\left(g_{i j} \cos \delta_{i j}-b_{i j} \sin \delta_{i j}\right) \\
& \frac{\partial q_{i j}}{\partial \delta_{i}}=-\frac{V_{i} V_{j}}{a}\left(g_{i j} \cos \delta_{i j}+b_{i j} \sin \delta_{i j}\right) \\
& \frac{\partial q_{i j}}{\partial \delta_{j}}=\frac{V_{i} V_{j}}{a}\left(g_{i j} \cos \delta_{i j}+b_{i j} \sin \delta_{i j}\right) \\
& \frac{\partial q_{i j}}{\partial V_{i}}=-2 V_{i}\left(\frac{b_{i j}}{a^{2}}+b_{s h i}\right)-\frac{V_{j}}{a}\left(g_{i j} \sin \delta_{i j}-b_{i j} \cos \delta_{i j}\right) \\
& \frac{\partial q_{i j}}{\partial V_{j}}=-\frac{V_{i}}{a}\left(g_{i j} \sin \delta_{i j}-b_{i j} \cos \delta_{i j}\right) \\
& \frac{\partial q_{j i}}{\partial \delta_{i}}=\frac{V_{i} V_{j}}{a}\left(g_{i j} \cos \delta_{i j}-b_{i j} \sin \delta_{i j}\right) \\
& \frac{\partial q_{j i}}{\partial \delta_{j}}=-\frac{V_{i} V_{j}}{a}\left(g_{i j} \cos \delta_{i j}-b_{i j} \sin \delta_{i j}\right) \\
& \frac{\partial q_{j i}}{\partial V_{i}}=\frac{V_{j}}{a}\left(g_{i j} \sin \delta_{i j}+b_{i j} \cos \delta_{i j}\right) \\
& \frac{\partial q_{j i}}{\partial V_{j}}=-2 V_{j}\left(b_{i j}+b_{s h j}\right)+\frac{V_{i}}{a}\left(g_{i j} \sin \delta_{i j}+b_{i j} \cos \delta_{i j}\right)
\end{aligned}
$$

To construct the $H$ matrix, initially all its elements are set to zero. Network elements are 
considered one-by-one. For the element between buses $i-j$, the partial derivatives of line flows with respect to $\delta_{i}, \delta_{j}, V_{i}$ and $V_{j}$ are computed using Eq. 15 to 30. These values are simply added to the corresponding elements of sub-matrices $H_{p i j}, \delta i, H_{p i j, \delta j,} H_{p i j}, V i, H_{p i j, V}, H_{p j i}$, ${ }_{\delta i}, H_{p j i, \delta j}, H_{p j i}, V i, H_{p j i}, V j, H_{q i j}, \delta i, H_{q i j, \delta j}, H_{q i j, V i}, H_{q i j, V j}, H_{q j i, \delta i}, H_{q j i,}, \delta j, H_{q j i, V i}$ and $H_{q j i, V j}$.

Sub-matrices $H_{P, \delta}, H_{P, V}, H_{Q, \delta}$ and $H_{Q, V}$ are now considered. Partial derivatives of bus powers can be expressed in terms of partial derivatives of line flows. To illustrate this let $i-j, i-k$ and $i-m$ be the elements connected at bus $i$. Then the bus powers $P_{i}$ and $Q_{i}$ are given by

Therefore

$$
\begin{aligned}
& P_{i}=p_{i j}+p_{i k}+p_{i m} \\
& Q_{i}=q_{i j}+q_{i k}+q_{i m}
\end{aligned}
$$

$$
\begin{aligned}
& \frac{\partial P_{i}}{\partial \delta_{i}}=\frac{\partial p_{i j}}{\partial \delta_{i}}+\frac{\partial p_{i k}}{\partial \delta_{i}}+\frac{\partial p_{i m}}{\partial \delta_{i}} \\
& \frac{\partial Q_{i}}{\partial \delta_{i}}=\frac{\partial q_{i j}}{\partial \delta_{i}}+\frac{\partial q_{i k}}{\partial \delta_{i}}+\frac{\partial q_{i m}}{\partial \delta_{i}}
\end{aligned}
$$

Similar expressions can be written for other partial derivatives of $P_{i}$ and $Q_{i}$ with respect to $\delta_{j}$, $V_{i}$ and $V_{j}$. Likewise considering bus powers $P_{j}$ and $Q_{j}$, partial derivatives of $P_{j}$ and $Q_{j}$ can also be obtained in terms of partial derivatives of line flows in the lines connected to bus $j$. It is to be noted that the partial derivatives of the line flows contribute to the partial derivatives of bus powers. Table 1 shows a few partial derivatives of line flows and the corresponding partial derivative of bus powers to which it contributes.

\begin{tabular}{c|c}
\hline \hline \multicolumn{2}{c}{ Partial Derivatives of } \\
\hline$\frac{\partial p_{i j}}{\partial \delta_{i}}, \frac{\partial p_{j i}}{\partial \delta_{j}}, \frac{\partial q_{i j}}{\partial V_{i}}, \frac{\partial q_{j i}}{\partial V_{j}}$ & $\frac{\partial P_{i}}{\partial \delta_{i}}, \frac{\partial P_{j}}{\partial \delta_{j}}, \frac{\partial Q_{i}}{\partial V_{i}}, \frac{\partial Q_{j}}{\partial V_{j}}$ \\
\hline \hline
\end{tabular}

Table 1. $\overline{\overline{\text { Partial Derivatives of Line Flows and the Corresponding Partial Derivatives }}}$ of Bus Powers.

The partial derivatives of $\frac{\partial p_{i j}}{\partial \delta_{i}}, \frac{\partial p_{i j}}{\partial \delta_{j}}, \frac{\partial p_{i j}}{\partial V_{i}}, \frac{\partial p_{i j}}{\partial V_{j}}$ will contribute to $\frac{\partial p_{i}}{\partial \delta_{i}}, \frac{\partial p_{i}}{\partial \delta_{j}}, \frac{\partial p_{i}}{\partial V_{i}}, \frac{\partial p_{i}}{\partial V_{j}}$

respectively. Similar results are true for $p_{j i}, q_{i j}$ and $q_{j i}$. Those values will be added to the corresponding elements of $H_{P, \delta}, H_{P, V}, H_{Q, \delta}$ and $H_{Q, V}$. This process is repeated for all the network elements. Once all the network elements are added, we get the final $H$ matrix.

\section{Computing and recording only the required partial derivatives alone}

The $H$ matrix will have $3 N+4 B$ number of rows if all possible measurements are available in the network. However, in practice, number of available measurements will be much less. 
Instead of computing elements of rows corresponding to unavailable measurements and then deleting them, proper logics can be adopted to compute and record only the required partial derivatives alone. When line $i-j$ is processed, it may not be always necessary to compute all the 16 partial derivatives given by Eq. 15 to 30 . The partial derivatives $\frac{\partial p_{i j}}{\partial \delta_{i}}, \frac{\partial p_{i j}}{\partial \delta_{j}}, \frac{\partial p_{i j}}{\partial V_{i}}$ and $\frac{\partial p_{i j}}{\partial V_{j}}$ are to be computed only when $p_{i j}$ or $P_{i}$ or both $p_{i j}$ and $P_{i}$ are in the available measurement list. Thus following three cases are possible.

CASE 1: $p_{i j}$ is an available measurement. The four partial derivatives are entered in row corresponding to $p_{i j}$.

CASE 2: $P_{i}$ is an available measurement. The four partial derivatives are added to previous values in the row corresponding to $P_{i}$.

CASE 3: $p_{i j}$ and $P_{i}$ are available measurements. The four partial derivatives are entered in the row corresponding to $p_{i j}$ and added to previous values in the row corresponding to $P_{i}$.

Such logics are to be followed for $\frac{\partial p_{j i}}{\partial \delta_{i}}, \frac{\partial p_{j i}}{\partial \delta_{j}}, \frac{\partial p_{j i}}{\partial V_{i}}, \frac{\partial p_{j i}}{\partial V_{j}} ; \frac{\partial q_{i j}}{\partial \delta_{i}}, \frac{\partial q_{i j}}{\partial \delta_{j}}, \frac{\partial q_{i j}}{\partial V_{i}}, \frac{\partial q_{i j}}{\partial V_{j}}$ and $\frac{\partial q_{j i}}{\partial \delta_{i}}, \frac{\partial q_{j i}}{\partial \delta_{j}}, \frac{\partial q_{j i}}{\partial V_{i}}, \frac{\partial q_{j i}}{\partial V_{j}}$ also.

\subsection{Application example to illustrate the construction of $H$ Jacobian matrix}

The three bus power system (Ali Abur \& A. G. Exposito 2004) as shown in Figure 3 is used to illustrate the construction of $H$ Jacobian matrix. In this system bus 1 is the slack bus and the tap setting " $a$ " for all lines are 1 . With the network data as listed in Table 2 and the available measurements as listed in Table 3, the Jacobian matrix $H$ is constructed as discussed in Section 5, taking the initial bus voltages as $V_{1}=V_{2}=V_{3}=1.0 \angle 0^{\circ}$.
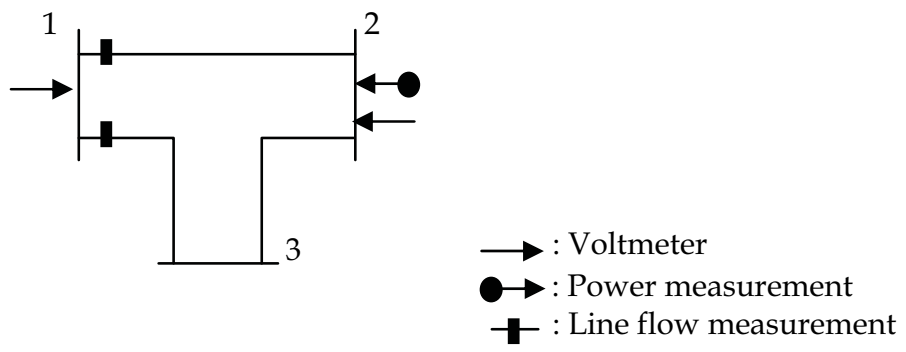

Fig. 3. Single-line diagram and measurement configuration of a 3-bus power system.

\begin{tabular}{|c|c|c|c|c|}
\hline \multicolumn{2}{|c|}{ Line } & \multirow[b]{2}{*}{$R(\mathrm{pu})$} & \multirow[b]{2}{*}{$X(\mathrm{pu})$} & \multirow{2}{*}{$\begin{array}{l}\text { Total Line Charging Susceptance } \\
\qquad B(\mathrm{pu})\end{array}$} \\
\hline From Bus & $\begin{array}{l}\text { To } \\
\text { Bus }\end{array}$ & & & \\
\hline 1 & 2 & 0.01 & 0.03 & 0 \\
\hline 1 & 3 & 0.02 & 0.05 & 0 \\
\hline 2 & 3 & 0.03 & 0.08 & 0 \\
\hline
\end{tabular}

Table 2. Network data for 3-bus system 


\begin{tabular}{ccc}
\hline \hline Measurements & Value $(\mathrm{pu})$ & Weightage \\
\hline$V_{1}$ & 1.006 & 62500 \\
$V_{2}$ & 0.968 & 62500 \\
$p_{1-2}$ & 0.888 & 15625 \\
$p_{1-3}$ & 1.173 & 15625 \\
$q_{1-2}$ & 0.568 & 15625 \\
$q_{1-3}$ & 0.663 & 15625 \\
$P_{2}$ & -0.501 & 10000 \\
$Q_{2}$ & -0.286 & 10000 \\
\hline \hline
\end{tabular}

Table 3. Available measurements for 3-bus system

Noting that $V_{1}$ and $V_{2}$ are available measurements, the sub-matrices of $H_{V, \delta}, H_{V, V}$ are obtained as

$$
\left[\begin{array}{ll}
H_{V_{1}, \delta} & H_{V_{1}, V} \\
H_{V_{2}, \delta} & H_{V_{2}, V}
\end{array}\right]=\left[\begin{array}{llllll}
0 & 0 & 0 & 1 & 0 & 0 \\
0 & 0 & 0 & 0 & 1 & 0
\end{array}\right]
$$

where $\delta$ spans from $\delta_{1}, \delta_{2}$ to $\delta_{3}$ and $V$ spans from $V_{1}, V_{2}$ to $V_{3}$.

To illustrate all the stages of constructing the other sub-matrices, the network elements are added one by one as shown below.

Iteration 1

Element 1-2 is added. The line flow measurements corresponding to this element are $p_{12}, p_{21}$, $q_{12}$ and $q_{21}$. All these measurements are categorized according to the three different cases as in Section 5. The $p_{12}$ will be categorized as CASE 1 since this measurement is one of the available measurements and $P_{1}$ is not an available measurement. Similarly, $q_{12}$ is also categorized as CASE 1. However, $p_{21}$ and $q_{21}$ are categorized as CASE 2 since these measurements will contribute to $P_{2}$ and $Q_{2}$ respectively; but they are not listed as the available measurements. The new constructed sub-matrices are:

$$
\left[\begin{array}{ll}
H_{p_{12}, \delta} & H_{p_{12}, V} \\
H_{p_{13}, \delta} & H_{p_{13}, V} \\
H_{q_{12}, \delta} & H_{q_{12}, V} \\
H_{q_{13}, \delta} & H_{q_{13}, V} \\
H_{P_{2}, \delta} & H_{P_{2}, V} \\
H_{Q_{2}, \delta} & H_{Q_{2}, V}
\end{array}\right]=\left[\begin{array}{cccccc}
30 & -30 & 0 & 10 & -10 & 0 \\
0 & 0 & 0 & 0 & 0 & 0 \\
-10 & 10 & 0 & 30 & -30 & 0 \\
0 & 0 & 0 & 0 & 0 & 0 \\
-30 & 30 & 0 & -10 & 10 & 0 \\
10 & -10 & 0 & -30 & 30 & 0
\end{array}\right]
$$

Element 1-3 is added. The line flow measurements corresponding to this element are $p_{13}, p_{31}$, $q_{13}$ and $q_{31}$. Now, $p_{13}$ and $q_{13}$ will be categorized as CASE 1 since these measurements are listed as the available measurements and $P_{1}$ and $Q_{1}$ are not the available measurements. However it is not necessary to compute the partial derivatives of $p_{31}$ and $q_{31}$ as they and $P_{3}$ and $Q_{3}$ are not in available measurements. With this, the constructed sub-matrices are: 


$$
\left[\begin{array}{ll}
H_{p_{12}, \delta} & H_{p_{12}, V} \\
H_{p_{13}, \delta} & H_{p_{13}, V} \\
H_{q_{12}, \delta} & H_{q_{12}, V} \\
H_{q_{13}, \delta} & H_{q_{13}, V} \\
H_{P_{2}, \delta} & H_{P_{2}, V} \\
H_{Q_{2}, \delta} & H_{Q_{2}, V}
\end{array}\right]=\left[\begin{array}{cccccc}
30 & -30 & 0 & 10 & -10 & 0 \\
17.24 & 0 & -17.24 & 6.89 & 0 & -6.89 \\
-10 & 10 & 0 & 30 & -30 & 0 \\
-6.89 & 0 & 6.89 & 17.24 & 0 & -17.24 \\
-30 & 30 & 0 & -10 & 10 & 0 \\
10 & -10 & 0 & -30 & 30 & 0
\end{array}\right]
$$

Element 2-3 is added. Following similar logics, $p_{23}$ and $q_{23}$ will fall under CASE 2 and the partial derivatives of $p_{32}$ and $q_{32}$ are not required. The constructed sub-matrices are:

$$
\left[\begin{array}{ll}
H_{p_{12}, \delta} & H_{p_{12}, V} \\
H_{p_{13}, \delta} & H_{p_{13}, V} \\
H_{q_{12}, \delta} & H_{q_{12}, V} \\
H_{q_{13}, \delta} & H_{q_{13}, V} \\
H_{P_{2}, \delta} & H_{P_{2}, V} \\
H_{Q_{2}, \delta} & H_{Q_{2}, V}
\end{array}\right]=\left[\begin{array}{cccccc}
30 & -30 & 0 & 10 & -10 & 0 \\
17.24 & 0 & -17.24 & 6.89 & 0 & -6.89 \\
-10 & 10 & 0 & 30 & -30 & 0 \\
-6.89 & 0 & 6.89 & 17.24 & 0 & -17.24 \\
-30 & 40.96 & -10.96 & -10 & 14.11 & -4.11 \\
10 & -14.11 & 4.11 & -30 & 40.96 & -10.96
\end{array}\right]
$$

The final $H$ matrix will be the combination of all the sub-matrices with the column corresponding to slack bus being deleted. Thus the constructed Jacobian matrix $H$ in the first iteration is

$$
H=\left[\begin{array}{ccccc}
0 & 0 & 1 & 0 & 0 \\
0 & 0 & 0 & 1 & 0 \\
-30 & 0 & 10 & -10 & 0 \\
0 & -17.24 & 6.89 & 0 & -6.89 \\
10 & 0 & 30 & -30 & 0 \\
0 & 6.89 & 17.24 & 0 & -17.24 \\
40.96 & -10.96 & -10 & 14.11 & -4.11 \\
-14.11 & 4.11 & -30 & 40.96 & -10.96
\end{array}\right]
$$

Using the above $H$ matrix, state variables are updated as $V_{1}=0.9997 \angle 0^{0} ; V_{2}=0.9743 \angle-0.021^{0}$; $V_{3}=0.9428 \angle-0.045^{0}$. All the above stages are repeated until the convergence is obtained in iteration 3 with the final state variables values as $V_{1}=0.9996 \angle 0^{0} ; V_{2}=0.9741 \angle-0.022^{0}$; $V_{3}=0.9439 \angle-0.048^{0}$. These estimates are same as obtained in NRSE method.

The suggested procedure is also tested on 5-bus system (Stagg,G.W. \& El-Abiad,A.H. 1968) and IEEE 14-bus system, IEEE 24-bus system, IEEE 30-bus system, IEEE 57-bus system, local utility 103-bus system, IEEE 118-bus system and IEEE 300-bus system. The final results of all the test systems agree with those obtained using NRSE method. The details are discussed in Section 7. 


\section{Simulation}

In order to simulate the NRSE algorithm, data obtained from power flow studies is used. The initial states of voltage vectors are commonly assumed to have a flat profile that means all the voltage phasors are of 1 p.u and in phase with each other, i.e. 0 degree. Meanwhile the convergence of the algorithm is tested using the following criteria:

$$
\max \left|\Delta x_{k}\right|=\varepsilon
$$

where $\varepsilon$ is a given by user, most of the cases is set to 0.001 .

The performance of the algorithm in simulation studies is assessed by comparing the estimated values of the states and the measured values of the state with the true value (from power flow solution) of the state. The performance indices in Eq. $32-35$ are used for this comparison.

$$
\begin{aligned}
& J_{\text {meas }}=\frac{1}{m} \sum_{i=1}^{m}\left(\frac{\underline{z}_{i}-\underline{z}_{i}^{t}}{\sigma_{i}}\right)^{2} \\
& J_{\text {est. }}=\frac{1}{m} \sum_{i=1}^{m}\left(\frac{\underline{\underline{z}}_{i}-\underline{z}_{i}^{t}}{\sigma_{i}}\right)^{2} \\
& R_{\text {ave. }}=\frac{1}{m} \sum_{i=1}^{m}\left(\frac{\left|\underline{\underline{z}}_{i}-\underline{z}_{i}^{t}\right|}{\sigma_{i}}\right) \\
& R_{\max }=\max \left[\frac{\left|\hat{\underline{z}}_{i}-\underline{z}_{i}^{t}\right|}{\sigma_{i}}\right] \mid
\end{aligned}
$$

The level of uncertainty on the measurements is indicated by the performance index $J_{\text {meas }}$. While the performance index of $J_{\text {est. }}$. shows how close are the estimated values to the measured value. The filtering process is considered good if the ratio of $J_{\text {est. }} / J_{\text {meas }}$ is less than one. The performance indices $R_{a v e}$ and $R_{\max }$ indicate the average and the maximum values of weighted residuals from the true values to compliment the general information of the indices $J_{\text {meas }}$ and $J_{\text {est. }}$. In the other hand, the true and the estimated values of the state variables are compared by

$$
E_{x}=\left(\frac{\left|\hat{\underline{x}}_{i}-\underline{x}_{i}^{t}\right|}{\underline{x}_{i}^{t}}\right) \times 100 \%
$$

Table 4 shows the summary of the general computational for the tested network. The convergence tolerance of 0.001 p.u. and the margin of error $5 \%$ is assigned to all tested network. The tested network shows no bad data is detected since the objective function $J$ is found less than the chi-square value. 


\begin{tabular}{|c|c|c|c|c|c|c|}
\hline $\begin{array}{l}\text { System } \\
\text { Bus }\end{array}$ & $\begin{array}{c}\text { Tolerance } \\
\varepsilon\end{array}$ & $\begin{array}{c}\text { Confidence } \\
\text { level } \\
\alpha\end{array}$ & $\begin{array}{c}\text { Degrees of } \\
\text { freedom } \\
N=m-n\end{array}$ & $\begin{array}{c}\text { Chi-Square } \\
\qquad \chi^{2} N, a\end{array}$ & $\begin{array}{c}\text { Objective } \\
\text { function } \\
J\end{array}$ & Iter. \\
\hline$\overline{5}$ & 0.001 p.u & $95 \%$ & 8 & $1.83 \mathrm{E}+01$ & 4.37E-03 & 3 \\
\hline IEEE 14 & 0.001 p.u & $95 \%$ & 26 & $3.89 \mathrm{E}+01$ & $1.19 \mathrm{E}+01$ & 4 \\
\hline IEEE 30 & 0.001 p.u & $95 \%$ & 57 & $7.79 \mathrm{E}+01$ & $7.45 \mathrm{E}+01$ & 4 \\
\hline IEEE 57 & 0.001 p.u & $95 \%$ & 192 & $2.25 \mathrm{E}+02$ & $1.92 \mathrm{E}+02$ & 7 \\
\hline 103-bus & 0.001 p.u & $95 \%$ & 574 & $6.31 \mathrm{E}+02$ & $4.60 \mathrm{E}+02$ & 6 \\
\hline IEEE 118 & 0.001 p.u & $95 \%$ & 289 & $3.32 \mathrm{E}+02$ & $3.00 \mathrm{E}+02$ & 7 \\
\hline IEEE 300 & 0.001 p.u & $95 \%$ & 954 & $1.03 \mathrm{E}+03$ & $1.00 \mathrm{E}+03$ & 8 \\
\hline
\end{tabular}

Table 4. The summary of computational results.

Table 5 depicted the analysis of state vector $x$ for 5-bus system. Meanwhile Table 6 depicted the analysis of state vector for IEEE 14-bus system.

\begin{tabular}{|c|c|c|c|c|c|c|}
\hline \multirow[b]{2}{*}{$\begin{array}{l}\text { Bus } \\
\text { no. }\end{array}$} & \multicolumn{2}{|c|}{ Voltage magnitude (p.u.) } & \multicolumn{2}{|c|}{ Voltage phase (degree) } & \multicolumn{2}{|c|}{$E_{x}(\%)$} \\
\hline & $\begin{array}{l}\text { TRUE } \\
|V|^{t}\end{array}$ & $\begin{array}{l}\text { Estimated } \\
\qquad|\hat{V}|\end{array}$ & $\begin{array}{c}\text { TRUE } \\
\delta^{t}\end{array}$ & $\begin{array}{c}\text { Estimated } \\
\hat{\boldsymbol{\delta}}\end{array}$ & $\Delta|V|$ & $\Delta \delta$ \\
\hline 1 & 1.06 & 1.06 & 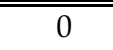 & 0 & 0 & 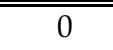 \\
\hline 2 & 1 & 1 & -2.061 & -2.06115 & 0 & 0.00728 \\
\hline 3 & 0.987 & 0.98725 & -4.64 & -4.6366 & 0.02533 & 0.07328 \\
\hline 4 & 0.984 & 0.98413 & -4.96 & -4.95691 & 0.01321 & 0.0623 \\
\hline 5 & 0.972 & 0.9717 & -5.76 & -5.76476 & 0.03086 & 0.08264 \\
\hline
\end{tabular}

Table 5. State Vector for 5-bus system.

Overall, this two network shows the performance of NRSE is good since the average of error for state vector is less than one for both network as shown in Table 7. To support the reliability of NRSE, the performance of indices for all tested network is shown in Table 8. It shows that the filtering process of the NRSE is acceptable since the ratio of $J_{\text {est }} / J_{\text {meas }}$. is less than one.

However, the most important performance index that can prove the aim of the research is achieved is the computer time. The computer time for this algorithm should be as short as possible as the size of the network becomes larger. Same as NRSE method, 5-bus system, IEEE 14-bus, IEEE 30-bus, IEEE 57-bus, local utility 103-bus, IEEE 118-bus and IEEE 300-bus system is tested. The results are compared with results obtained for existing NRSE method. The final estimate of the proposed method compare with the actual and NRSE method is shown in Figure 4 to 7 for 5-bus system, IEEE 14-bus, IEEE 30-bus and IEEE 57-bus respectively. Due to space limitation, the results of final estimate for local utility 103-bus, IEEE 118-bus and IEEE 300-bus system are not furnished in this section. The final estimated results of the proposed method are exactly the same as results obtained in NRSE. 


\begin{tabular}{|c|c|c|c|c|c|c|}
\hline \multirow[b]{2}{*}{$\begin{array}{c}\text { Bus } \\
\text { no. }\end{array}$} & \multicolumn{2}{|c|}{ Voltage magnitude (p.u.) } & \multicolumn{2}{|c|}{ Voltage phase (degree) } & \multicolumn{2}{|c|}{$E_{x}(\%)$} \\
\hline & TRUE $|V|^{t}$ & $\begin{array}{l}\text { Estimated } \\
\qquad|\hat{V}|\end{array}$ & $\begin{array}{c}\text { TRUE } \\
\delta^{t}\end{array}$ & $\begin{array}{c}\text { Estimated } \\
\hat{\boldsymbol{\delta}}\end{array}$ & $\Delta|V|$ & $\Delta \delta$ \\
\hline 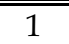 & 1.06 & 1.06071 & 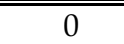 & 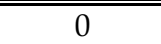 & 0.06698 & 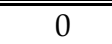 \\
\hline 2 & 1.045 & 1.04551 & -4.98 & -4.99057 & 0.0488 & 0.21225 \\
\hline 3 & 1.01 & 1.0105 & -12.72 & -12.75775 & 0.0495 & 0.29678 \\
\hline 4 & 1.019 & 1.01249 & -10.33 & -10.2318 & 0.63886 & 0.95063 \\
\hline 5 & 1.02 & 1.0165 & -8.78 & -8.75767 & 0.34314 & 0.25433 \\
\hline 6 & 1.07 & 1.07042 & -14.22 & -14.4546 & 0.03925 & 1.64979 \\
\hline 7 & 1.062 & 1.05997 & -13.37 & -13.25646 & 0.19115 & 0.84921 \\
\hline 8 & 1.09 & 1.09076 & -13.36 & -13.25655 & 0.06972 & 0.77433 \\
\hline 9 & 1.056 & 1.05337 & -14.94 & -14.83789 & 0.24905 & 0.68347 \\
\hline 10 & 1.051 & 1.05239 & -15.1 & -15.04667 & 0.13225 & 0.35318 \\
\hline 11 & 1.057 & 1.05759 & -14.79 & -14.87054 & 0.05582 & 0.54456 \\
\hline 12 & 1.055 & 1.05389 & -15.07 & -15.30079 & 0.10521 & 1.53145 \\
\hline 13 & 1.05 & 1.04744 & -15.16 & -15.33827 & 0.24381 & 1.17592 \\
\hline 14 & 1.036 & 1.03124 & -16.04 & -16.08195 & 0.45946 & 0.26153 \\
\hline
\end{tabular}

Table 6. State Vector for IEEE 14-bus system.

\begin{tabular}{c|c|c|c|c|c}
\hline $\begin{array}{c}\text { System } \\
\text { Bus }\end{array}$ & $\boldsymbol{J}_{\text {meas. }}$ & $\boldsymbol{J}_{\text {est. }}$ & $\boldsymbol{R}_{\text {ave }}$ & $\boldsymbol{R}_{\text {max }}$ & $\boldsymbol{J}_{\text {est }} / \mathbf{J}_{\text {meas. }}$ \\
& & & & & \\
\hline \hline 5 & 0.0115 & 0.0088 & 0.0274 & 0.3861 & 0.7638 \\
IEEE 14 & 0.5713 & 0.2257 & 0.0881 & 1.5950 & 0.3952 \\
IEEE 30 & 1.0942 & 0.6221 & 0.0668 & 2.0470 & 0.5685 \\
IEEE 57 & $1.00 \mathrm{E}+05$ & $4.76 \mathrm{E}+04$ & $8.21 \mathrm{E}-01$ & $1.65 \mathrm{E}+03$ & 0.4748 \\
103 & 1.1473 & 0.7844 & 0.0413 & 6.3426 & 0.6837 \\
IEEE 118 & $1.12 \mathrm{E}+00$ & $5.69 \mathrm{E}-01$ & $6.14 \mathrm{E}-04$ & $3.96 \mathrm{E}+00$ & 0.5096 \\
IEEE 300 & $1.09 \mathrm{E}+00$ & $6.45 \mathrm{E}-01$ & $3.09 \mathrm{E}-02$ & $4.65 \mathrm{E}+00$ & 0.5943 \\
\hline \hline
\end{tabular}

Table 7. Performance Indices 
Newton-Raphson State Estimation

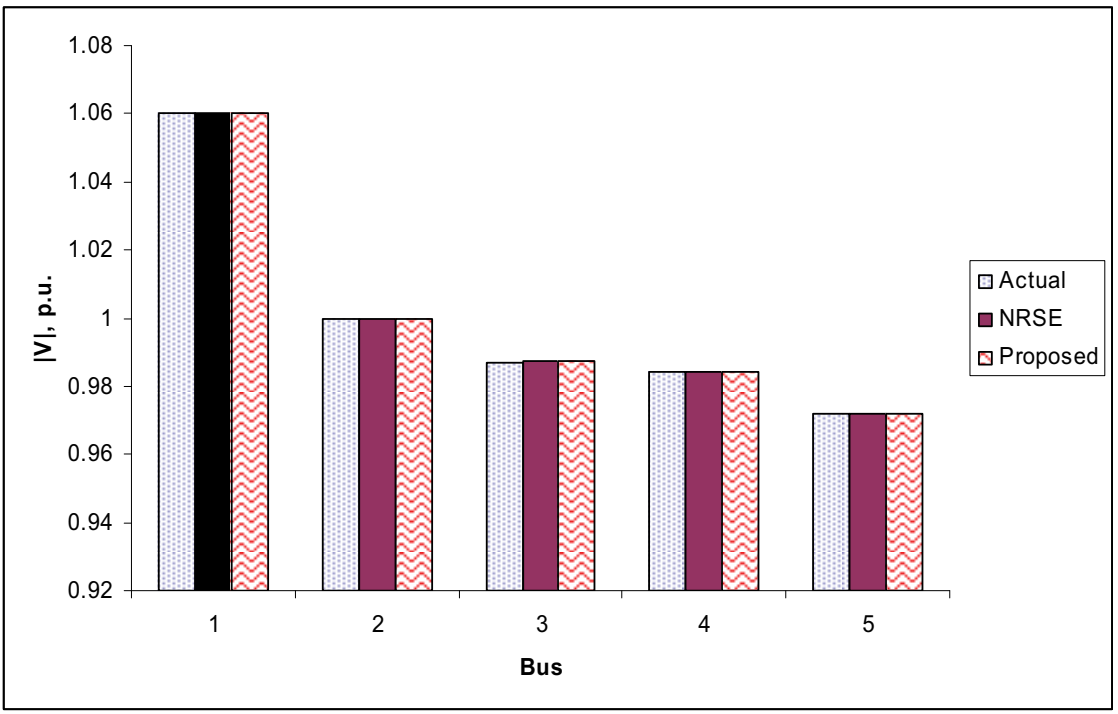

(a)

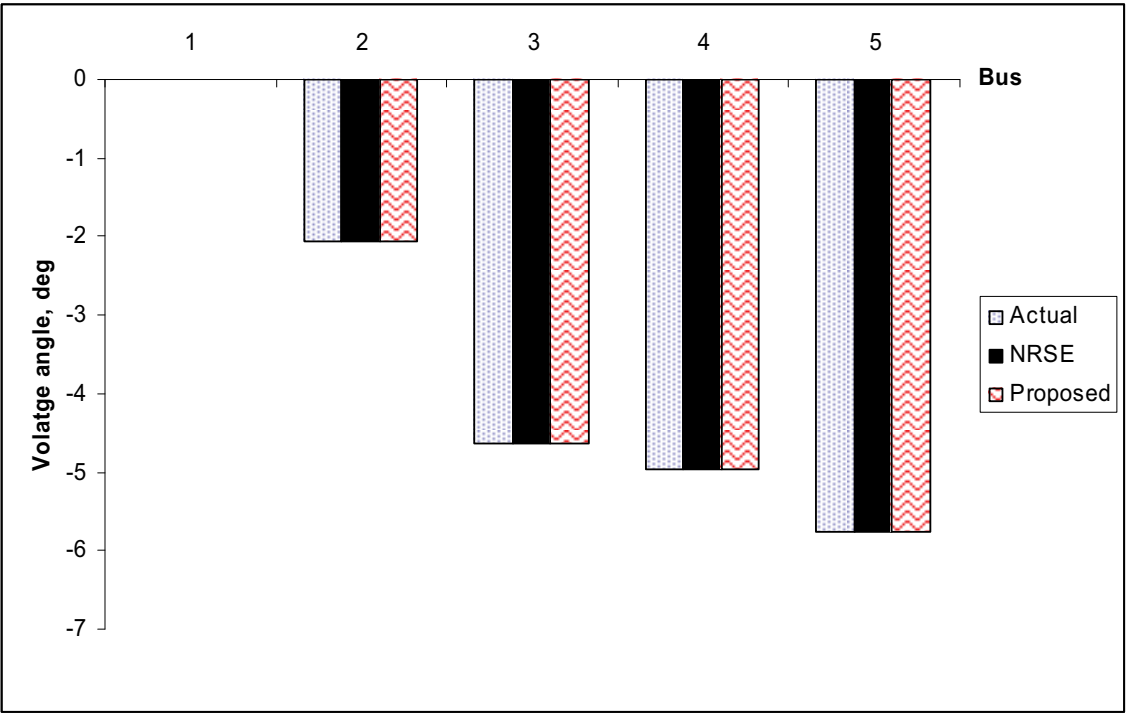

(b)

Fig. 4. (a) \& (b) The final estimate for voltage vector of 5-bus system. 


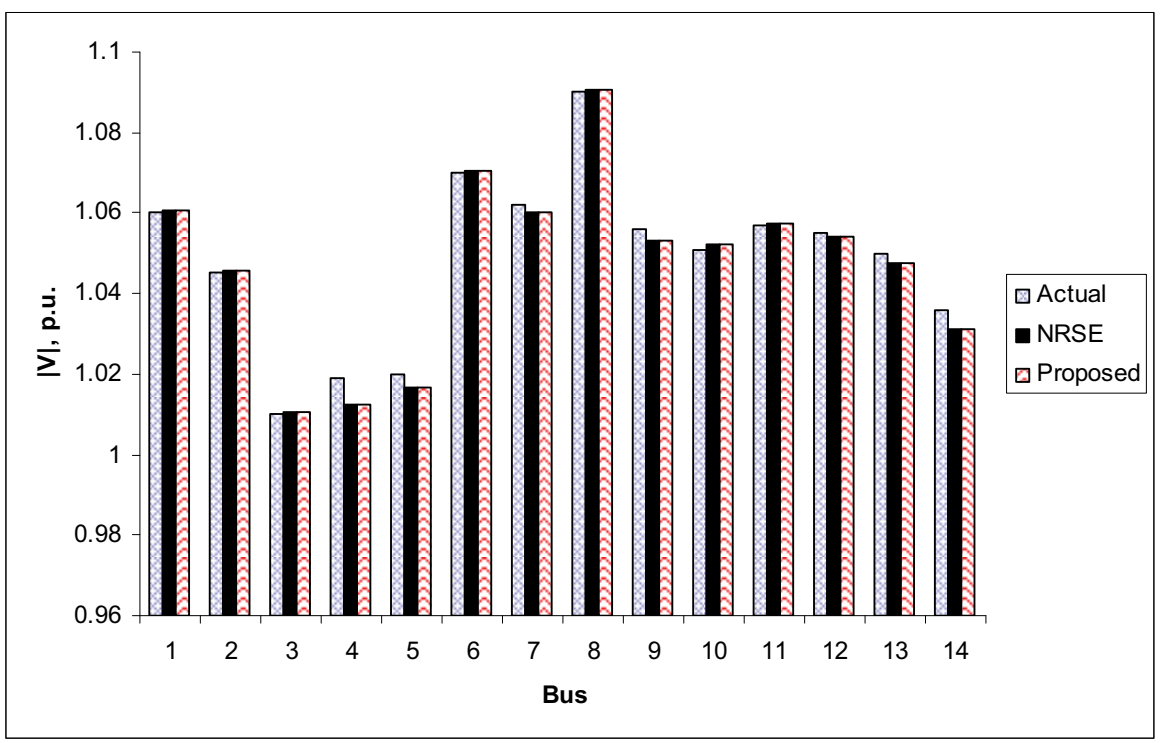

(a)

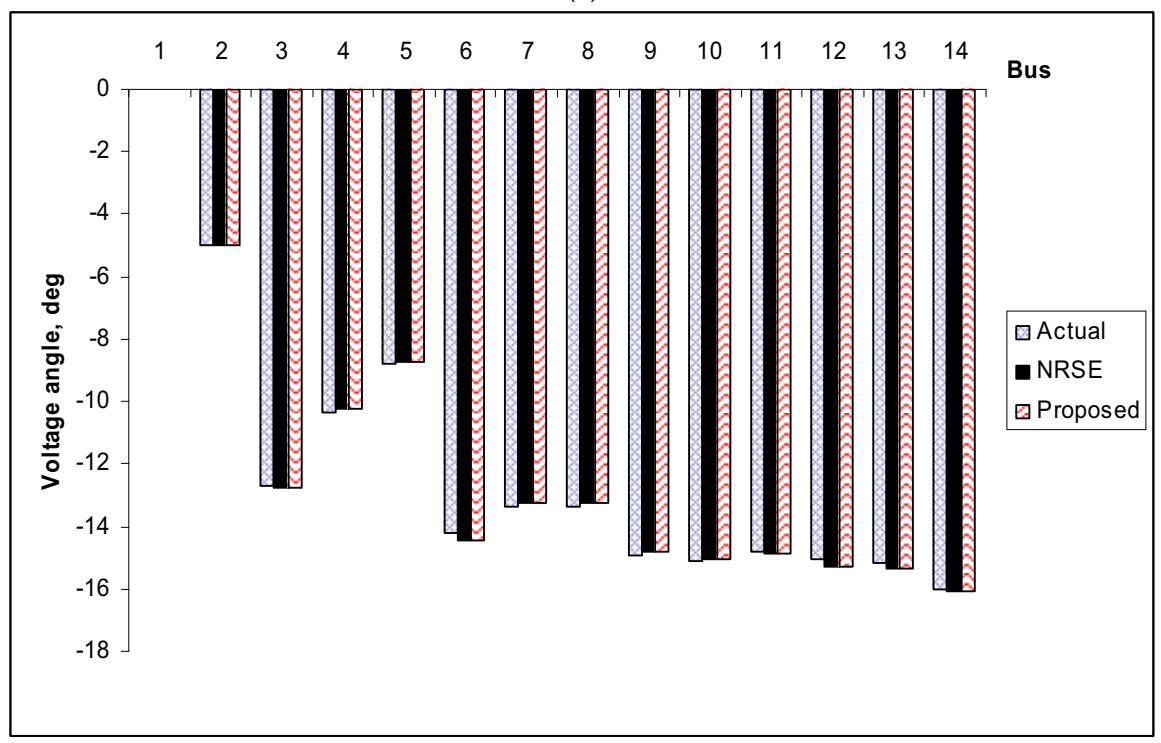

(b)

Fig. 5. (a) \& (b) The final estimate for voltage vector of IEEE 14-bus system. 


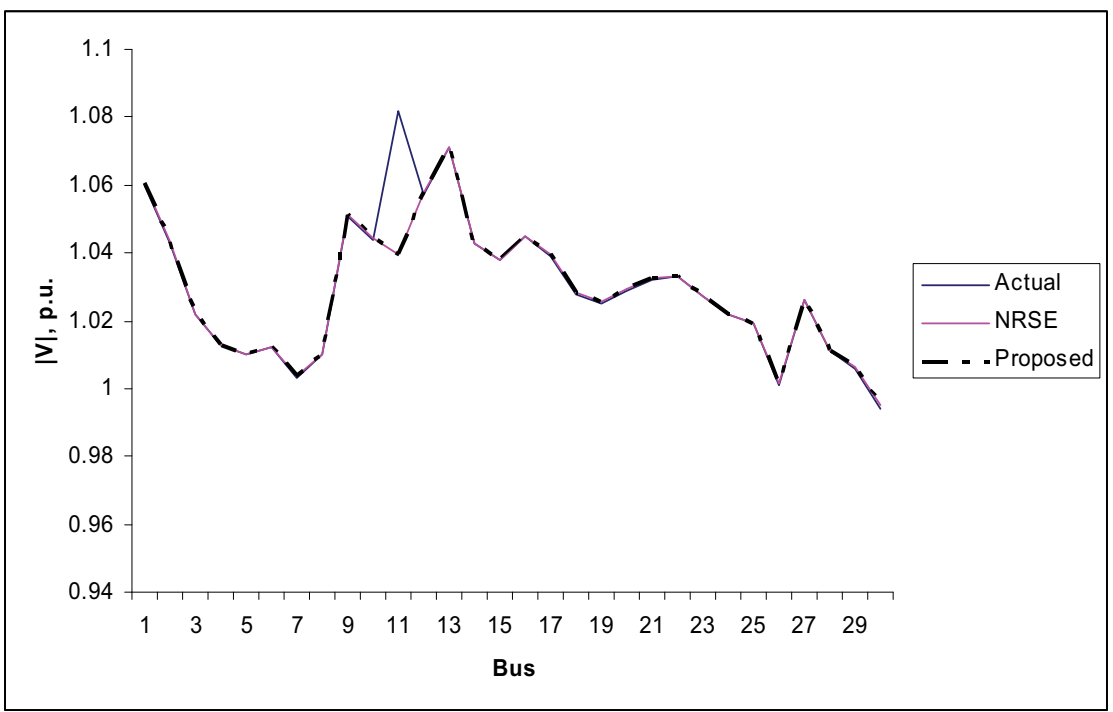

(a)

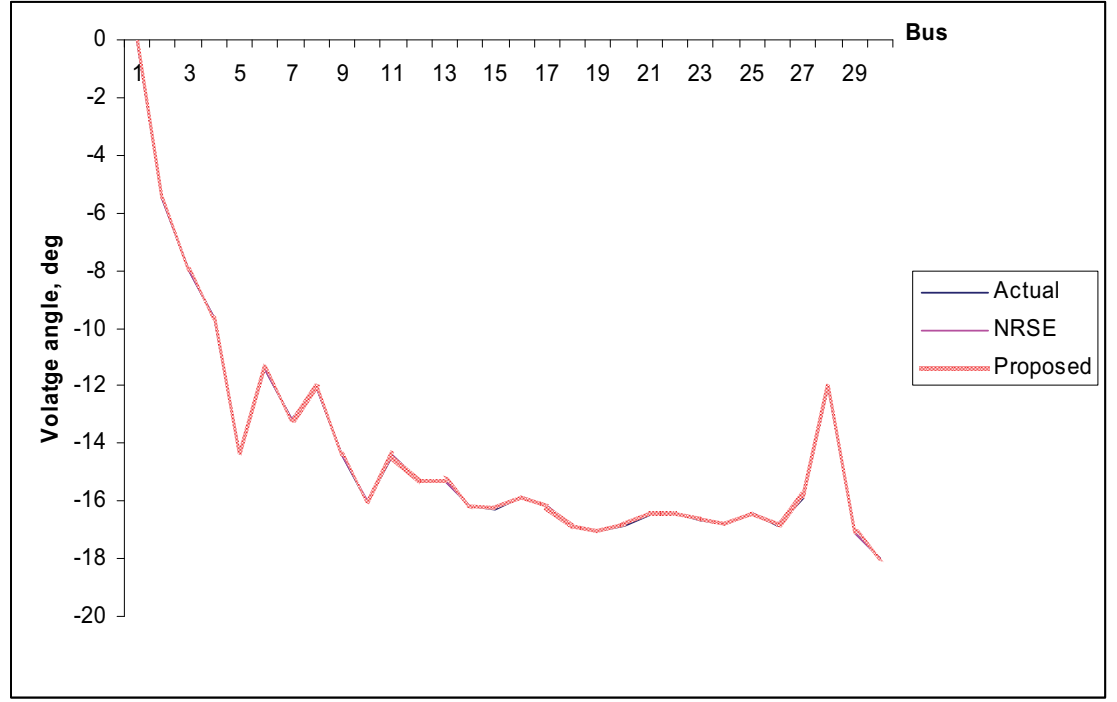

(b)

Fig. 6. (a) \& (b) The final estimate for voltage vector of IEEE 30-bus system. 


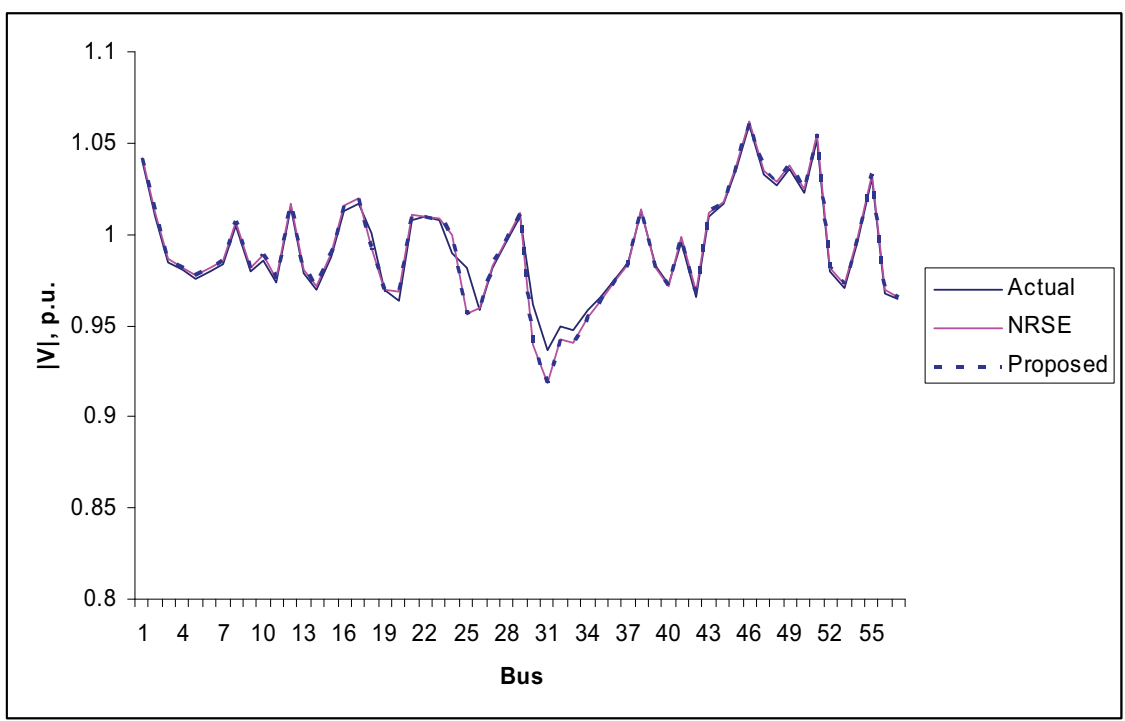

(a)

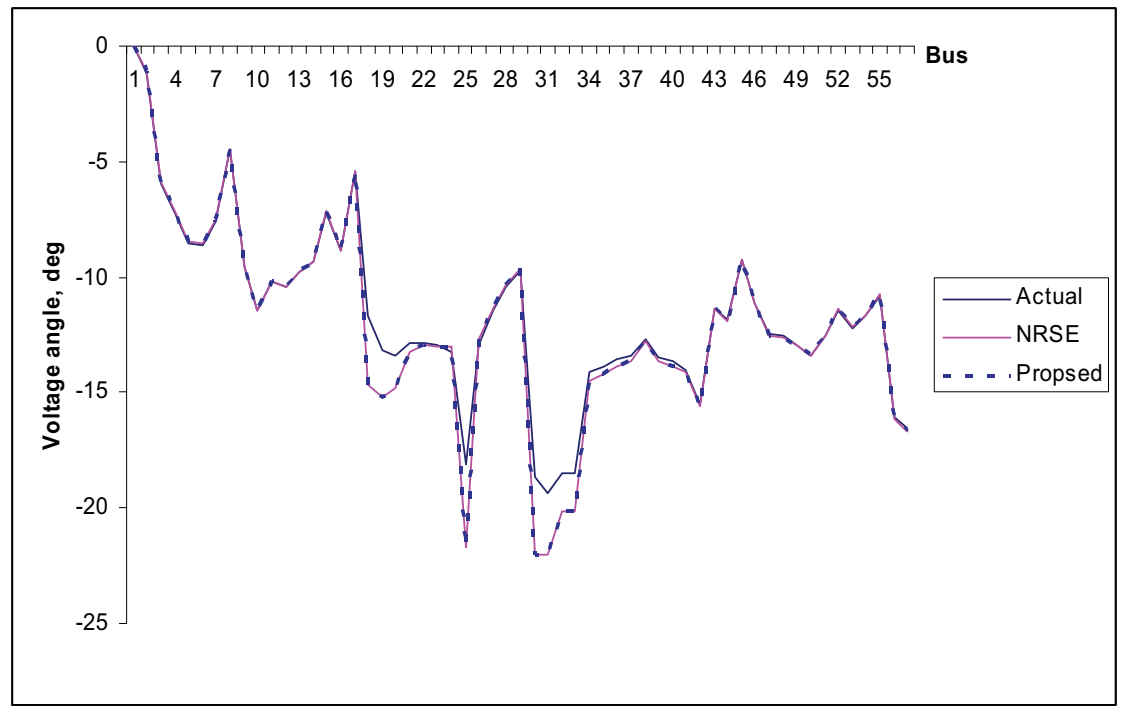

(b)

Fig. 7. (a) \& (b) The final estimate for voltage vector of IEEE 57-bus system.

On the other hand, the proposed method is certainly advantageous by considering the performance computational speed. Table 9 shows the average processor time taken for the overall process. The overall algorithm is developed using Matlab 7.0 and the programs are tested on computer with the CPU time of $504 \mathrm{MB}$ of RAM and the speed of CPU is Pentium(R) $3.40 \mathrm{GHz}$. 


\begin{tabular}{c|ccccc|ccc}
\multirow{2}{*}{$\begin{array}{c}\text { System } \\
\text { bus }\end{array}$} & $\begin{array}{c}\text { H time } \\
\text { sec }\end{array}$ & $\begin{array}{c}\text { G time } \\
\text { sec }\end{array}$ & $\begin{array}{c}\text { BD time } \\
\text { sec }\end{array}$ & $\begin{array}{c}\text { Conv time } \\
\text { sec }\end{array}$ & $\begin{array}{c}\text { Total } \\
\text { sec }\end{array}$ & $\begin{array}{c}H \text { time } \\
\text { sec }\end{array}$ & $\begin{array}{c}\text { G time } \\
\text { sec }\end{array}$ & $\begin{array}{c}\text { BD time } \\
\text { sec }\end{array}$ \\
\hline \hline 5 & $3.13 \mathrm{E}-02$ & $1.88 \mathrm{E}-01$ & $9.38 \mathrm{E}-02$ & $4.69 \mathrm{E}-02$ & $3.28 \mathrm{E}-01$ & $1.56 \mathrm{E}-01$ & $5.16 \mathrm{E}-01$ & $9.38 \mathrm{E}-02$ \\
IEEE 14 & $3.13 \mathrm{E}-02$ & $2.19 \mathrm{E}-01$ & $9.38 \mathrm{E}-02$ & $7.81 \mathrm{E}-02$ & $3.75 \mathrm{E}-01$ & $2.66 \mathrm{E}-01$ & $6.56 \mathrm{E}-01$ & $9.38 \mathrm{E}-02$ \\
IEEE 30 & $3.13 \mathrm{E}-02$ & $3.28 \mathrm{E}-01$ & $1.09 \mathrm{E}-01$ & $4.69 \mathrm{E}-02$ & $5.63 \mathrm{E}-01$ & $2.81 \mathrm{E}-01$ & $7.66 \mathrm{E}-01$ & $1.25 \mathrm{E}-0$ \\
IEEE 57 & $1.09 \mathrm{E}-01$ & $9.84 \mathrm{E}-01$ & $1.56 \mathrm{E}-01$ & $1.72 \mathrm{E}-01$ & $1.38 \mathrm{E}+00$ & $4.84 \mathrm{E}-01$ & $1.33 \mathrm{E}+00$ & $1.56 \mathrm{E}-0$ \\
103 & $1.22 \mathrm{E}+00$ & $8.16 \mathrm{E}+00$ & $8.28 \mathrm{E}-01$ & $1.02 \mathrm{E}+00$ & $1.37 \mathrm{E}+01$ & $5.00 \mathrm{E}-01$ & $3.31 \mathrm{E}+00$ & $8.44 \mathrm{E}-0$ \\
IEEE 118 & $1.52 \mathrm{E}+00$ & $1.13 \mathrm{E}+01$ & $1.41 \mathrm{E}-01$ & $4.69 \mathrm{E}-01$ & $1.54 \mathrm{E}+01$ & $2.97 \mathrm{E}-01$ & $4.56 \mathrm{E}+00$ & $4.69 \mathrm{E}-0$ \\
IEEE 300 & $2.52 \mathrm{E}+01$ & $2.28 \mathrm{E}+02$ & $1.05 \mathrm{E}+01$ & $3.48 \mathrm{E}+00$ & $3.03 \mathrm{E}+02$ & $4.25 \mathrm{E}+00$ & $8.33 \mathrm{E}+01$ & $9.75 \mathrm{E}+0$ \\
\hline \hline
\end{tabular}

Note : $H$ time is the time taken to build Jacobian Matrix; $G$ time is the time taken to build the Gain $\mathrm{N}$ taken to process the bad data algorithm.

Table 9. Processor Time Comparison of NRSE vs Proposed method. 
For the sake of analysis, the tabulated data in Table 9 is converted in graph figure as shown in Figure 8 to 10. It is clearly show that processor time increases considerably when size of network become larger. This applied to the both methods. However, comparing the two methods, the proposed method uses significantly less processor time than that of the NRSE method when the size of network becomes larger.

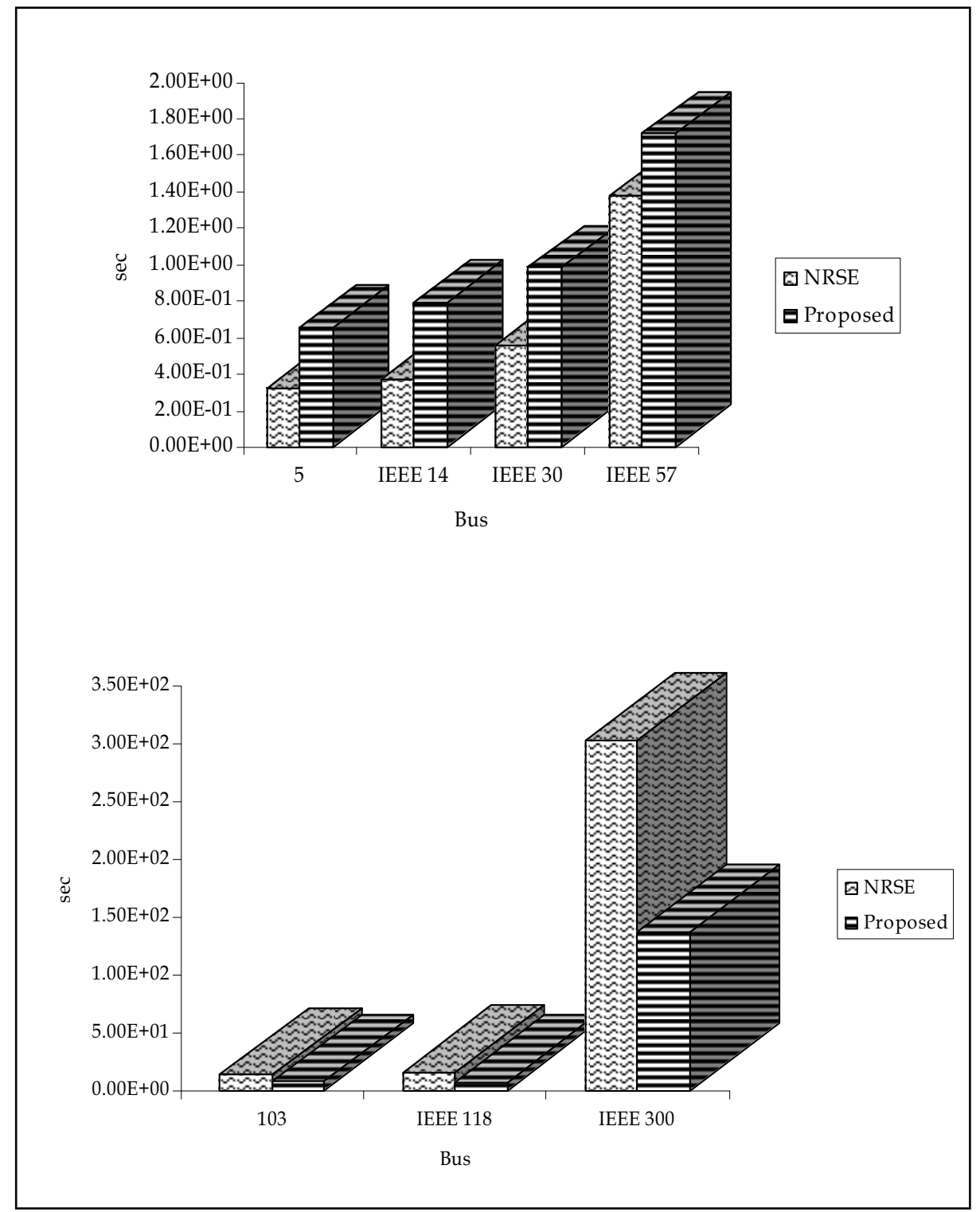

Fig. 8. Total processing time comparison of NRSE vs Proposed method. 
Newton-Raphson State Estimation

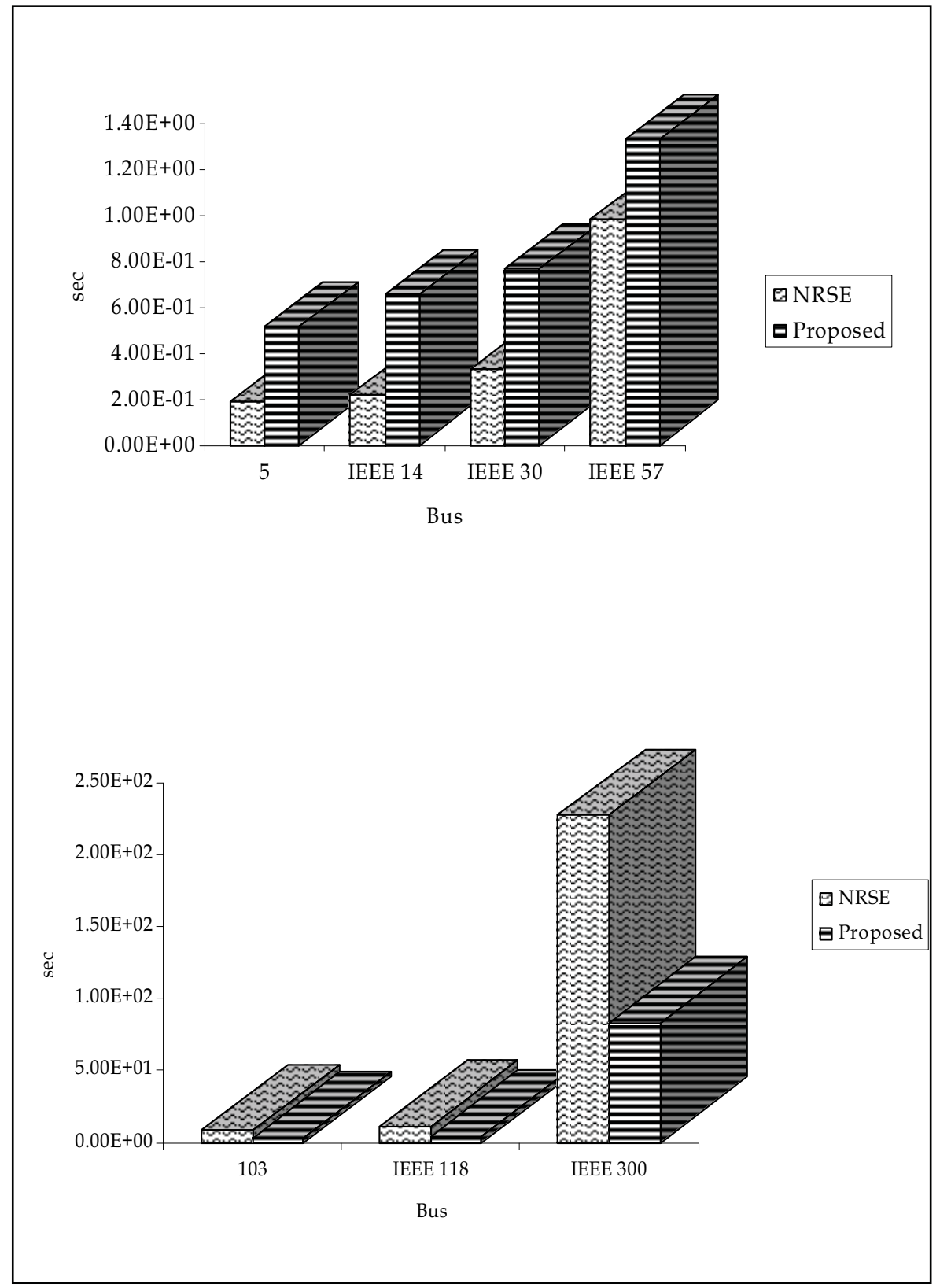

Fig. 9. Formation of Gain time comparison of NRSE vs Proposed method. 


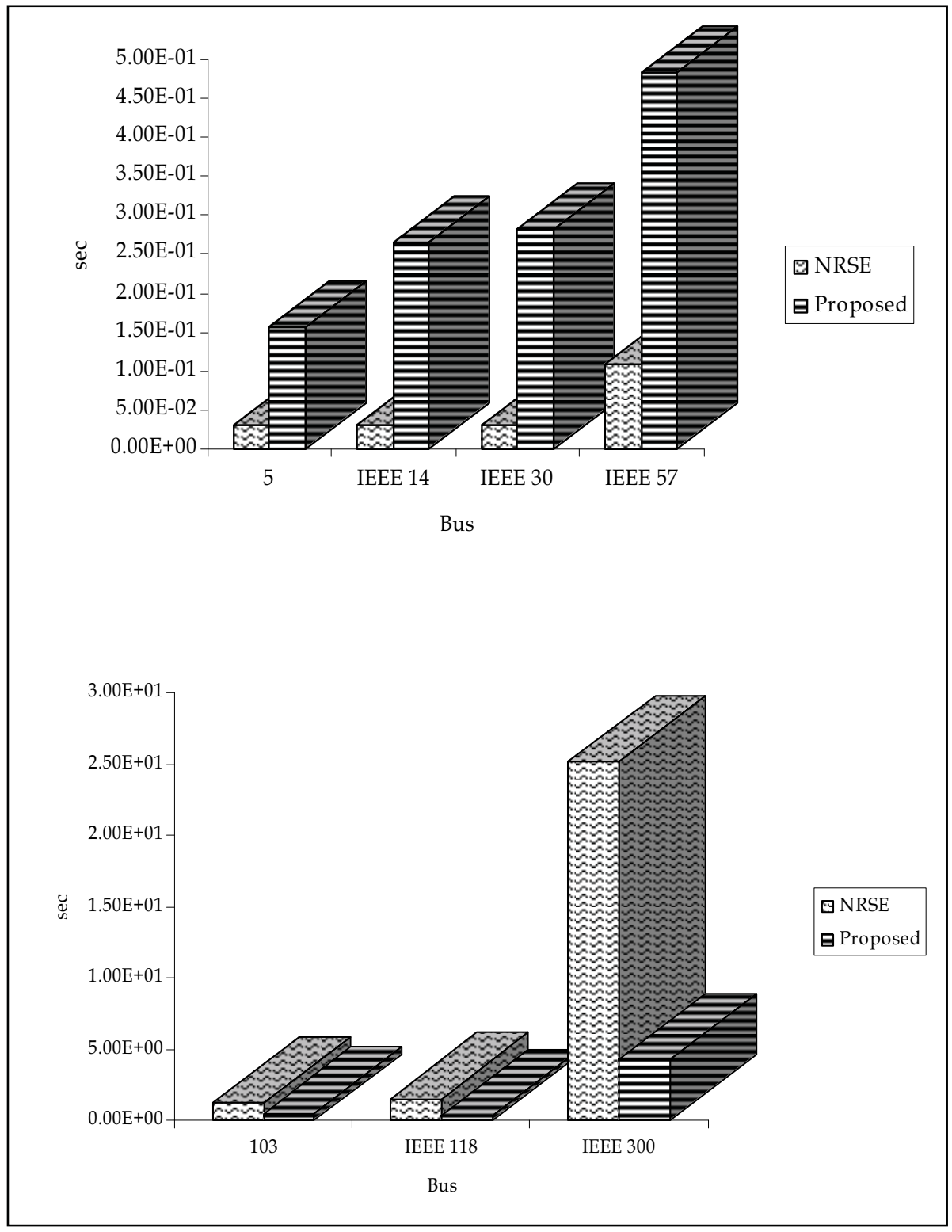

Fig. 10. Formation of Jacobian time comparison of NRSE vs Proposed method. 


\section{Discussion.}

It has been illustrated in Figures 8 through 10 that the proposed method does not provide any advantage when applied to a small network. However, the advantages of the proposed method can be seen when it is applied to a large network. Processing time reduction is achieved when the network size is large. To understand this phenomenon, let us examine an $N$-bus network with a maximum number of measurements where $N$ is number of busses and $\mathrm{Nbr}$ is number of branches. The assumptions made for the case of full measurements are as follows:

- All active power $(\mathrm{P})$ and reactive power $(\mathrm{Q})$ are measured at the sending and receiving end of each transmission line

- Active and reactive power injection, as well as voltage magnitude are measured at each bus in the system

- The number of states $(2 N-1)$ is approximately equal to $2 N$.

In NRSE method, the sub-matrix $H_{V}$, shown in Eq. 13 and Eq. 14 , is constant, i.e. 0 or 1. Therefore they need not to be computed at each iteration resulting in very small computation time. The sub-matrices of $H_{p i j}, H_{p j i}, H_{q i j}$ and $H_{q j i}$ have exactly the same zero and nonzero structures as the network branches. This is because each line flow is incident to its two terminal buses. Thus, these sub-matrices are sparse and may not take longer time to compute. On the other hand, the sub-matrices of $H_{P}$ and $H_{Q}$ involve derivatives of real and reactive power injections into the buses. When the measurement set is full, the sub matrix in matrix $H_{P}$ and $H_{Q}$ will be of size $N \times N$. Each sub-matrix will have $N$ diagonal terms and $N^{2}$ off-diagonal terms. For each diagonal term, $N$ numbers of trigonometric functions are to be evaluated and for each off-diagonal term, one trigonometric function is to be evaluated. Therefore,

total number of trigonometric functions that are to be evaluated $=8 \mathrm{~N}^{2}$

In the proposed method, the sub-matrix of $H_{V}$ is the same as in NRSE method. However, the rest of the sub-matrices totally depends on 16 numbers of partial derivatives of line flows, shown in Eq. 15 through Eq. 30. For each partial derivative of line flow, 2 trigonometric functions are to be evaluated. Meanwhile, to compute calculated powers, 4 numbers of line flows, shown in Eq. 6 through Eq. 9 are to be computed. For each calculated power, 2 trigonometric functions are to be evaluated. Therefore the number of trigonometric functions that are to be evaluated is equal to $32 \mathrm{Nbr}+8 \mathrm{Nbr}$. Taking $\mathrm{Nbr}=1.4 \mathrm{~N}$,

total number of trigonometric functions that are to be evaluated $=56 \mathrm{~N}$

Based on Eq. (37) and Eq. (38), we can conclude that the proposed method uses significantly less number of mathematical operations and hence takes less CPU time particularly for larger networks compared to the NRSE method.

\section{Conclusion.}

Newton-Raphson State Estimation (NRSE) method using bus admittance matrix remains as an efficient and most popular method to estimate the state variables. In this method, 
elements of Jacobian matrix $H$ are computed from standard expressions which lack physical significance. The process of computing the elements of the Jacobian matrix is significantly time consuming step which requires evaluation of large number of trignometric functions. It is significant, especially in large scale power system networks. In order to reduce the computation time, a simple algorithm to construct the $H$ matrix is presented in this chapter. This can be easily fit into the NRSE method.

It is recognized that each element of the $H$ matrix is contributed by the partial derivatives of the power flows in the network elements. The elements of the state estimation Jacobian matrix are obtained considering the power flow measurements in the network elements. Network elements are processed one-by-one and the $H$ matrix is updated in a simple manner. The final $H$ matrix thus constructed is exactly same as that obtained in available NRSE method.

Systematically constructed Jacobian matrix $H$ is then integrated with WLS method to estimate the state variables. The final estimates and time taken to converge are recorded and compared with results obtained from NRSE method available in the literature. The results proved that the suggested method takes lesser computer time compared with available NRSE method, particularly when the size of the network becomes larger. The suggested procedure is successfully tested on IEEE standard systems and found to be efficient.

\section{Acknowledgements}

The authors gratefully acknowledge University Technology PETRONAS, Malaysia for providing the facilities and financial support to carry out the studies.

\section{References}

A. Monticelli (2002), Electric Power System State Estimation, Proceedings IEEE, Vol. 88, No. 2, pp. 262-282.

F.C. Schweppe; J. Wildes \& D.B. Rom (1970), Power system static-state estimation, parts I, II and III, IEEE Transactions on Power Apparatus and Systems, Vol. PAS-89, No. 1, pp.120-135.

Ali Abur \& Antonio Gomez Exposito (2004), Power System Estimation: Theory and Implementation, Marcel Dekker, Inc., New York.

Holten, L.; Gjelsvik, A.; Aam, S.; Wu, F.F. \& Liu, W.-H.E (1988), Comparison of different methods for state estimation, IEEE Transactions on Power Systems, Vol. 3, No 4, pp. $1798-1806$.

A. Garcia; A. Monticelli \& P. Abreu (1979), Fast decoupled state estimation and bad data processing, IEEE Transactions on Power Apparatus and Systems, Vol. PAS-98, No. 5, pp.1645-1651.

F. C. Schweppe \& E. J. Handschin (1974), Static state estimation in electric power systems, Proceedings IEEE, Vol. 62, No. 7, pp. 972-983.

A. Garcia; A. Monticelli \& P. Abreu (1979), Fast decoupled state estimation and bad data processing, IEEE Transactions on Power Apparatus and Systems, Vol. PAS-98, No. 5, pp.1645-1651.

A, Monticelli \& A. Garcia (1990), Fast decoupled state estimators, IEEE Transactions on Power Systems, Vol. 5, No. 2, pp. 556-564. 
A. Simoes-Costa \& V. H. Quintana (Feb. 1981), A robust numerical technique for power system state estimation, IEEE Transactions on Power Apparatus and Systems, Vol. PAS-100, No. 2, pp. 691-698.

A. Simoes-Costa \& V. H. Quintana (August 1981), An orthogonal row processing algorithm for power system sequential state estimation, IEEE Transactions on Power Apparatus and Systems, Vol. PAS-100, No. 8, pp. 3791-3800.

Slutsker I.W. Vempatin \& W.F. Tinney, Orthogonal Sparse Vector Methods, IEEE Transactions on Power Systems, Vol. 7, No. 2, pp. 926-932.

Holten, L.; Gjelsvik, A.; Aam, S.; Wu, F.F.\& Liu, W.-H.E (1988), Comparison of different methods for state estimation, IEEE Transactions on Power Systems, Vol. 3, No 4, pp. 1798 - 1806.

B Stott \& O Alsac (1974), Fast Decoupled Load Flow, IEEE Transactions on Power Apparatus and Systems, Vol. PAS-93, No. 3, pp. 859-869.

A. Monticelli (1999), State Estimation in Electric Power Systems. A Generalized Approach, Kluwer Academic Publishers, New York.

John J. Grainger \& William D. Stevenson, Jr. (1994), Power System Analysis, McGraw-Hill International Editions, New York.

Stagg,G.W. \& El-Abiad,A.H. (1968), Computer Methods in Power System Analysis, McGrawHill Book Company, New York. 


\section{Advanced Technologies}

Edited by Kankesu Jayanthakumaran

ISBN 978-953-307-009-4

Hard cover, 698 pages

Publisher InTech

Published online 01, October, 2009

Published in print edition October, 2009

This book, edited by the Intech committee, combines several hotly debated topics in science, engineering, medicine, information technology, environment, economics and management, and provides a scholarly contribution to its further development. In view of the topical importance of, and the great emphasis placed by the emerging needs of the changing world, it was decided to have this special book publication comprise thirty six chapters which focus on multi-disciplinary and inter-disciplinary topics. The inter-disciplinary works were limited in their capacity so a more coherent and constructive alternative was needed. Our expectation is that this book will help fill this gap because it has crossed the disciplinary divide to incorporate contributions from scientists and other specialists. The Intech committee hopes that its book chapters, journal articles, and other activities will help increase knowledge across disciplines and around the world. To that end the committee invites readers to contribute ideas on how best this objective could be accomplished.

\section{How to reference}

In order to correctly reference this scholarly work, feel free to copy and paste the following:

Nursyarizal Mohd Nor, Ramiah Jegatheesan and Ir. Perumal Nallagowden (2009). Newton-Raphson State Estimation Solution Employing Systematically Constructed Jacobian Matrix, Advanced Technologies, Kankesu Jayanthakumaran (Ed.), ISBN: 978-953-307-009-4, InTech, Available from:

http://www.intechopen.com/books/advanced-technologies/newton-raphson-state-estimation-solution-

employing-systematically-constructed-jacobian-matrix

\section{INTECH}

open science | open minds

\author{
InTech Europe \\ University Campus STeP Ri \\ Slavka Krautzeka 83/A \\ 51000 Rijeka, Croatia \\ Phone: +385 (51) 770447 \\ Fax: +385 (51) 686166 \\ www.intechopen.com
}

\author{
InTech China \\ Unit 405, Office Block, Hotel Equatorial Shanghai \\ No.65, Yan An Road (West), Shanghai, 200040, China \\ 中国上海市延安西路65号上海国际贵都大饭店办公楼 405 单元 \\ Phone: +86-21-62489820 \\ Fax: $+86-21-62489821$
}


(C) 2009 The Author(s). Licensee IntechOpen. This chapter is distributed under the terms of the Creative Commons Attribution-NonCommercial-ShareAlike-3.0 License, which permits use, distribution and reproduction for non-commercial purposes, provided the original is properly cited and derivative works building on this content are distributed under the same license. 